\title{
Exercise in a behavioural weight control programme for obese patients with Type 2 (non-insulin-dependent) diabetes
}

\author{
R. R. Wing, L.H. Epstein, M.Paternostro-Bayles, A. Kriska, M.P. Nowalk and W.Gooding \\ University of Pittsburgh School of Medicine, Pittsburgh, Penn, USA
}

\begin{abstract}
Summary. Two studies were conducted to determine whether adding exercise to a diet programme promotes weight loss or glycaemic control in Type 2 (non-insulin-dependent) diabetic subjects. In Study 1, 25 subjects were randomly assigned to diet plus moderate exercise or diet plus placebo exercise. All subjects exercised twice a week as a group and once a week on their own; the diet plus moderate exercise group walked a 3 -mile route at each session while the diet plus placebo exercise group did very low intensity exercises such as stretching and light calisthenics. All subjects followed a calorie-counting diet and were taught behaviour modification strategies. Weight losses and improvements in glycaemic control did not differ significantly between the two treatment groups at the end of the 10-week treatment or at 1-year follow-up. In Study 2, more extreme conditions were compared: a diet only group and a diet plus exercise group. The diet plus exercise group walked a 3-mile route with the group 3 times/week and once a week on their own, while the diet only group was instructed to maintain their current low level of activity. Both
\end{abstract}

groups received comparable diet and behaviour modification instruction and therapist contacts. The diet plus exercise group had significantly $(p<0.01)$ better weight losses than the diet only condition at the end of the 10 week programme $(-9.3 \mathrm{~kg}$ vs $-5.6 \mathrm{~kg})$ and at 1 year follow-up $(-7.9 \mathrm{~kg}$ vs $-3.8 \mathrm{~kg}$ ). Both groups had similar improvements in glycosylated haemoglobin, but reductions in medication were more frequent and greater in magnitude in the diet plus exercise group. Finally, analyses were conducted collapsing across studies and across treatment groups and comparing subjects who reported low, medium, or high levels of exercise at 1 year. Self-reported exercise was related to weight loss and to improvements in glycosylated haemoglobin, even after adjusting for weight loss. These data suggest that the combination of diet and exercise improves weight loss and glycaemic control compared to diet only in Type 2 diabetic patients.

Key words: Type 2 (non-insulin-dependent) diabetes, exercise, diet, behaviour modification, weight loss.
Weight loss is considered the cornerstone of therapy for obese individuals with Type 2 (non-insulin-dependent) diabetes, since weight loss lowers blood glucose and increases insulin sensitivity [1-3]. However, it remains difficult for obese diabetic patients, like obese individuals in general, to lose weight and maintain their losses [4].

Several recent studies with non-diabetic obese subjects [5-8] have suggested that exercise may be important in promoting weight loss and maintenance. In these studies, the combination of diet plus exercise produced better long-term weight losses than either diet or exercise alone. The combination of diet plus exercise would appear to be particularly advantageous for Type 2 diabetic patients, since exercise may have independent effects on glycaemic control [9-11], insulin sensitivity $[12,13]$ and serum lipid levels [14]. However, previous studies with patients with Type 2 diabetes and glucose intolerance have failed to find consistent differences between diet only and diet plus exercise programmes [15-17] in either weight loss or glycaemic improvement.

The present studies were designed to determine whether the combination of diet plus exercise would im- prove weight loss, glycaemic control, or cardiovascular risk factors in obese Type 2 diabetic patients compared to diet alone. In the first study, a diet plus moderate exercise programme was compared to a diet plus placebo exercise programme. In the second study, two more extreme conditions were compared: diet only and diet plus exercise. These studies differed from previous studies with diabetic patients in several ways. First, the present studies used walking as the form of the exercise and emphasised distance rather than intensity. This approach to exercise is recommended for weight loss [18] and seems more appropriate for the older, sedentary patient with Type 2 diabetes than the more vigorous forms of aerobic exercise usually used in research studies. Secondly, to control for the non-specific effects of participating in an exercise programme, the first study compared a diet programme which included a moderate intensity exercise programme based on walking, with a diet programme which included a placebo exercise. Finally, since the effects of exercise on weight loss are often not observed during initial treatment [5-8], these studies followed patients for a full year after treatment. 
Table 1. Characteristics of subjects entering study 1 and study 2. (mean \pm SD)

\begin{tabular}{|c|c|c|c|c|}
\hline & \multicolumn{2}{|l|}{ Study 1} & \multicolumn{2}{|l|}{ Study 2} \\
\hline$n$ & 12 & 13 & 15 & 15 \\
\hline Age & $56.2 \pm 7.5$ & $52.5 \pm 8.9$ & $56.1 \pm 6.4$ & $55.1 \pm 7.2$ \\
\hline Weight (kg) & $102.9 \pm 18.2$ & $98.9 \pm 13.5$ & $106.9 \pm 20.8$ & $102.0 \pm 19.4$ \\
\hline $\mathrm{HbA}_{1}$ & $9.8 \pm 1.5$ & $9.6 \pm 1.8$ & $10.7 \pm 1.9$ & $10.9 \pm 1.8$ \\
\hline Years diabetic & $4.3 \pm 3.5$ & $4.8 \pm 6.0$ & $7.0 \pm 5.3$ & $7.0 \pm 6.1$ \\
\hline \multicolumn{5}{|l|}{ Treatment regimen } \\
\hline diet only $n=$ & 6 & 7 & 2 & 1 \\
\hline oral $n=$ & 6 & 6 & 10 & 9 \\
\hline
\end{tabular}

$n=$ number of subjects participating in study

\section{Subjects and method}

\section{Subjects}

Twenty-five subjects (21 F; $4 \mathrm{M}$ ) were recruited for Study 1 and 30 subjects $(21 \mathrm{~F} ; 9 \mathrm{M})$ for Study 2 . No subjects who participated in Study 1 were allowed to participate in Study 2. To be eligible for the studies, subjects were required to be $>20 \%$ above ideal weight, aged $30-65$, and to meet the National Diabetes Data Group [19] criteria for Type 2 diabetes. Subjects were excluded from the study if they had a known history of coronary heart disease, were taking medications that would interfere with weight loss or with measurement of heart rate during exercise, or had orthopaedic problems that would limit walking. In Study 1, subjects were excluded if they were on insulin. Characteristics of the subjects in the two studies are shown in Table 1.

\section{Method}

Study 1. Subjects in Study 1 were randomly assigned to one of two treatment conditions which differed only in the intensity of exercise prescribed: diet plus moderate exercise (DPME) or diet plus placebo exercise (DPPE). Both groups participated in a behavioural weight control programme, with group meetings held twice a week for ten weeks and monthly for the following six months. Each meeting consisted of an individual weigh-in, measurement of postprandial blood glucose, and a lecture-discussion related to behaviour modification for weight control (see below).

Diet. All subjects were given a daily calorie goal designed to produce approximately $1 \mathrm{~kg}$ /week weight loss. The calorie goal was calculated by taking the patient's pre-treatment weight (in $\mathrm{kg}$ ), multiplying by 26 and subtracting 1000 calories. Calorie books and self-monitoring diaries were distributed, and subjects were asked to monitor their caloric intake throughout the programme attempting to stay below their calorie goal. Although no specific diet was prescribed, subjects were taught to increase their intake of complex carbohydrates, and decrease their intake of fat, in keeping with the revised American Diabetes Association dietary guidelines [20].

Behavioural strategies. Subjects in both treatment groups were taught standard behaviour modification strategies for changing their eating habits. These included techniques for slowing down the rate of eating, reducing eating signals in the home environment, dealing with social pressures to eat, pre-planning for special events, and relapse prevention. To help motivate subjects to lose weight and attend treatment sessions, subjects were asked to deposit $\$ 85$ at the start of the pro- gramme. Portions of this deposit were refunded for weight loss, attendance at meetings, and exercise at both treatment meetings and at home.

Medication changes. Blood glucose levels were measured at each treatment meeting. The physician on the project used these blood glucose values as the basis for making adjustments in diabetes medication.

Exercise. All subjects exercised twice a week as a group and once a week on their own, with each exercise session lasting approximately one hour. The two groups differed in the type and intensity of the exercise that was prescribed. The DPME programme involved moderate exercise based on walking. Walking was selected as the form of exercise because it was deemed most appropriate for 55 year old, very overweight patients. Subjects gradually increased the speed and distance they walked until they were walking 3 miles within the one hour session. Subjects in the DPPE condition were provided with a low intensity exercise programme, consisting of light calisthenics and flexibility exercises set to music (which we have called "flexercise"). The flexercise programme was tape-recorded so that patients could complete the $60 \mathrm{~min}$ routine once a week at home. This placebo exercise programme was develloped to control for the non-specific social and psychological aspects of exercise.

Study 2. Subjects in Study 2 were randomly assigned to diet only $(n=15)$ or diet plus exercise $(n=15)$. The treatment procedures utilised were identical to Study 1, with the following exceptions. Both groups attended treatment sessions 3 times/week (versus 2 times/week in Study 1) for 10 weeks. After this intensive training period, subjects met weekly for an additional 10 weeks and then monthly for a year.

Subjects in the diet plus exercise group walked a 3 mile route with therapists at each of their three meetings/week, and were instructed to exercise additionally once per week on their own. Subjects in the diet only condition were instructed not to change their baseline level of activity. Their three meetings/week were used to provide demonstration and films of new low-calorie cooking techniques, to practice new behaviours such as portion size estimation, and to role play techniques such as asking waiters for low-calorie alternatives. To control for the social aspect of the exercise condition, the diet only condition had numerous group activities, including dinner at a restaurant and trips to the grocery store to identify low calorie food items.

Measures. The following measures were obtained at weeks 0,10 , and 62 , in both studies, unless otherwise specified. Subjects fasted for $12 \mathrm{~h}$ prior to blood sampling and those on oral hypoglycaemic medication 
omitted both their evening and morning dose of medication. Patients were instructed to refrain from structured exercise for $72 \mathrm{~h}$ before laboratory measurement.

Weight was measured in street clothes, without shoes, using a balance beam scale. Percent overweight was calculated by comparing the subject's weight to the ideal weight for height specified on the Metropolitan Life Insurance Norms [21]. Body mass index, which provides an estimate of body fat, was calculated by the formula $\left(\mathrm{kg} / \mathrm{m}^{2}\right)$.

Blood pressure was measured according to protocol procedures utilized in the Multiple Risk Factor Intervention Trial [22]. Measurements were taken by a nurse who had been certified to measure blood pressure. Subjects were seated, and normal or obese size cuffs were used as appropriate. Three measurements were taken, with at least a $30 \mathrm{~s}$ intermeasurement interval. The mean of the last two measures served as the primary measure of blood pressure. The nurse was unaware of the treatment assignment or weight loss of the subjects. Blood pressure was not measured at one-year follow-up.

Total cholesterol and triglycerides were measured using enzymatic procedures; triglycerides were measured on the glycerol obtained after hydrolysis with lipase [23, 24]. High density lipoprotein cholesterol (HDL-C) was analysed by enzymatic procedures done on the supernatant obtained after heparin-manganese precipitation [25].

Plasma glucose and insulin were measured fasting and at $30 \mathrm{~min}$ and $60 \mathrm{~min}$ after ingestion of an $8 \mathrm{oz}$. can of Ensure (Ross Laboratory, Columbus, Ohio, USA) in Study 1. In Study 2, glucose and insulin were measured $0,15,30,60$, and 120 min after a $75 \mathrm{~g}$ oral glucose load. Plasma glucose was analysed using a Beckman Glucose Analyser (Beckman Instruments, Inc., Fullerton, Calif, USA). Insulin was analysed by radioimmunoassay [26]. Glycosylated haemoglobin $\left(\mathrm{HbA}_{1}\right)$, which provides an integrated measure of blood glucose control over a 2-3 month period [27], was analysed at the Diabetes Research Laboratory of Children's Hospital of Pittsburgh. Saline incubated samples were used to measure $\mathrm{HbA}_{1}$ by column chromatography (Isolab minicolumns, Akron, Ohio, USA) using a water bath at approximately $22^{\circ} \mathrm{C}$ and low, medium and high control samples [28]. The laboratory normal for $\mathrm{HbA}_{1}$ is $6.1 \pm 0.5 \%$.

All patients completed the Paffenbarger Activity Questionnaire [29], a self-report measure of activity, which asks about blocks walked, stairs climbed, and other activities during the preceding week. The questionnaire can be scored to give an estimate of caloric expenditure from walking and overall caloric expenditure during the preceding week.

In Study 2, caloric intake was assessed at pre-treatment and posttreatment by 3-day food records. Subjects reported their intake on two working days and one non-working day. Food records were documented by trained nutritionists and analysed using a computerised database of nutrient values.

\section{Statistical analysis}

Repeated measures analysis of variance were used to analyse the data in each study. Treatment group (DPME/DPPE or Diet Plus Exercise/Diet Only) was used as a between group factor and time (pre/post or pre/ 1 year) as a repeated measure. The analyses were done individually for each of the dependent measures using the BMDP programme, 1981 edition.

\section{Results}

\section{Study I}

Ten of the 12 subjects in the DPME group and 12 of the 13 subjects in the DPPE group completed the initial 10 week program. Attendance at the exercise sessions was excellent and did not differ for the two treatment groups. Patients in the DPME group attended an average of 19.2 of the 20 group exercise sessions and re-
Table 2. Physiological changes from pre-treatment to post-treatment (week 10) for subjects in diet plus moderate exercise (DPME) and diet plus placebo exercise (DPPE) groups

\begin{tabular}{|c|c|c|c|c|c|}
\hline & $\begin{array}{l}\text { Diet plus } \\
\text { moderate } \\
\text { exercise } \\
(n=10) \\
\text { mean } \pm \text { SEM }\end{array}$ & \multicolumn{2}{|c|}{$\begin{array}{l}\text { Diet plus } \\
\text { placebo } \\
\text { exercise } \\
(n=12) \\
\text { mean } \pm \text { SEM }\end{array}$} & $\begin{array}{l}p \text {-value } \\
\text { of time } \\
\text { effect }\end{array}$ & $\begin{array}{l}p \text {-value } \\
\text { of time } x \\
\text { group } \\
\text { interaction }\end{array}$ \\
\hline \multicolumn{6}{|c|}{ Weight $(\mathrm{kg})$} \\
\hline Pre & $106.9 \pm 5.3$ & 97.4 & \pm 3.8 & & \\
\hline Post & $98.4 \pm 5.3$ & 90.1 & \pm 3.9 & $<0.001$ & NS \\
\hline \multicolumn{6}{|c|}{ Body mass index $\left(\mathrm{kg} / \mathrm{m}^{2}\right)$} \\
\hline Pre & $39.48 \pm 1.89$ & 37.19 & $9 \pm 1.81$ & & \\
\hline Post & $36.34 \pm 1.91$ & 34.40 & $0 \pm 1.80$ & $<0.001$ & NS \\
\hline \multicolumn{6}{|c|}{$\mathrm{HbA}_{1}(\%)$} \\
\hline Pre & $9.7 \pm 0.5$ & 9.4 & \pm 0.5 & & \\
\hline Post & $8.0 \pm 0.4$ & 7.9 & \pm 0.5 & $<0.001$ & NS \\
\hline \multicolumn{6}{|c|}{ Cholesterol (mmol/1) } \\
\hline Pre & $5.51 \pm 0.42$ & 5.80 & $0 \pm 0.23$ & & \\
\hline Post & $5.33 \pm 0.31$ & 5.12 & $2 \pm 0.18$ & $<0.01$ & NS \\
\hline \multicolumn{6}{|c|}{ HDL-Cholesterol (mmol/1) } \\
\hline Pre & $0.95 \pm 0.08$ & 0.99 & $9 \pm 0.06$ & & \\
\hline Post & $0.90 \pm 0.07$ & 0.98 & $8 \pm 0.06$ & NS & NS \\
\hline \multicolumn{6}{|c|}{ Triglycerides ${ }^{\mathrm{b}}(\mathrm{mmol} / \mathrm{l})$} \\
\hline Pre & $2.10 \pm 0.17$ & 2.93 & $3 \pm 0.68$ & & \\
\hline Post & $1.90 \pm 0.18$ & 1.94 & $4 \pm 0.32$ & $<0.05$ & NS \\
\hline \multicolumn{6}{|c|}{ Systolic blood pressure $(\mathrm{mm} \mathrm{Hg})$} \\
\hline Pre & $137 \pm 3$ & 140 & \pm 3 & & \\
\hline Post & $126 \pm 2$ & 127 & \pm 4 & $<0.001$ & NS \\
\hline \multicolumn{6}{|c|}{ Diastolic blood pressure $(\mathrm{mm} \mathrm{Hg})$} \\
\hline Pre & $86 \pm 2$ & 87 & \pm 2 & & \\
\hline Post & $80 \pm 2$ & 79 & \pm 1 & $<0.001$ & NS \\
\hline \multicolumn{6}{|c|}{ Plasma glucose (mmol) } \\
\hline $\begin{array}{l}\text { min } \\
\text { Pre }\end{array}$ & $10.2 \pm 0.8$ & 9.9 & \pm 0.8 & & \\
\hline Post & $7.6 \pm 0.8$ & 7.8 & \pm 0.9 & $<0.001$ & NS \\
\hline \multicolumn{6}{|c|}{$30 \mathrm{~min}$} \\
\hline Pre & $12.9 \pm 0.9$ & 12.6 & \pm 0.8 & & \\
\hline Post & $10.1 \pm 0.9$ & 9.9 & \pm 0.9 & $<0.001$ & NS \\
\hline \multicolumn{6}{|c|}{$60 \mathrm{~min}$} \\
\hline Pre & $14.3 \pm 1.2$ & 14.6 & \pm 0.9 & & \\
\hline Post & $10.9 \pm 1.3$ & 11.3 & \pm 1.2 & $<0.001$ & NS \\
\hline \multicolumn{6}{|c|}{ Insulin (pmol/l) } \\
\hline Pre & \pm 17 & 145 & \pm 14 & & \\
\hline Post & $76 \pm 10$ & 93 & \pm 14 & $<0.001$ & NS \\
\hline \multicolumn{6}{|c|}{$30 \mathrm{~min}$} \\
\hline Pre & \pm 52 & 340 & \pm 42 & & \\
\hline Post & $270 \quad \pm 37$ & 265 & \pm 47 & $<0.01$ & NS \\
\hline \multicolumn{6}{|c|}{$60 \mathrm{~min}$} \\
\hline Pre & \pm 57 & 451 & \pm 70 & & \\
\hline Post & $364 \pm 51$ & 382 & \pm 68 & $<0.01$ & NS \\
\hline
\end{tabular}

${ }^{a} p$-value of change from pre-treatment to post-treatment $;{ }^{b}$ Triglyceride values were converted to logarithms for analysis

ported exercising on 8 of the 9 sessions at home, while patients in the DPPE group attended 18.2 of the 20 sessions and reported exercise on 7.2 of the 9 sessions at home. Heart rate during the exercise sessions differed significantly $(p<0.01)$ between the DPME and DPPE groups (106 vs $87 \mathrm{bpm})$ as did caloric expenditure $(p<0.001)$ based on heart rate-workload curves (322 vs $127 \mathrm{kcal}$ expended/session). 


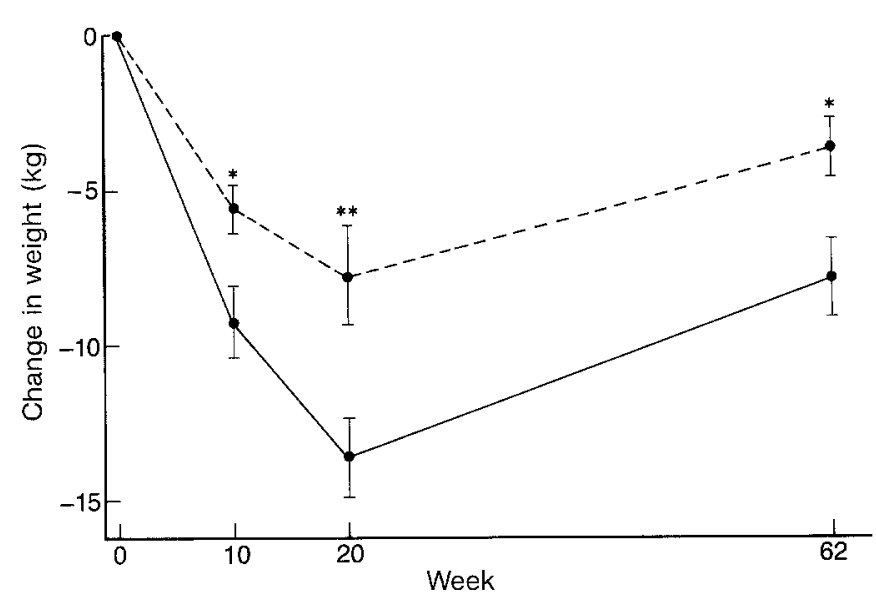

Fig. 1. Changes in weight at week 10,20, and 62 for patients in diet

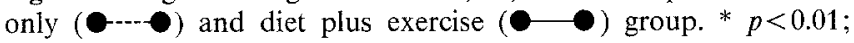
$* * p<0.001, \mathrm{I}=\mathrm{SEM}$

The analyses of variance showed significant main effects of time $(p<0.001)$ but non-significant $(p>0.10)$ interaction effects of group $\mathrm{x}$ time for weight and all physiological parameters studied, with the exception of HDL-C (Table 2). Thus, participation in the study produced improvements in weight and physiological parameters, but the walking programme did not produce greater weight losses or changes in glycaemic control than participation in placebo exercise. Weight losses during the initial 10-week programme were $8.5 \pm 0.8 \mathrm{~kg}$ (Mean \pm SEM) for the DPME condition and $7.3 \pm 0.7 \mathrm{~kg}$ for the DPPE group. Reductions in hypoglycaemic medication also occurred equally often for patients in the two treatment groups. Looking at the sub-sample of subjects treated with diet only, reductions in $\mathrm{HbA}_{1}$ were comparable for subjects in the DPME group $\left(n=6 ; \mathrm{HbA}_{1}\right.$ of $9.3 \%$ at pre and $7.6 \%$ at 10 weeks) and the DPPE group ( $n=6 ; \mathrm{HbA}_{1}$ of $9.5 \%$ at pre and $7.9 \%$ at 10 weeks).

One year follow-up was completed by 8 patients in the DPME group and 11 in the DPPE group. Thus, overall attrition was somewhat greater in the DPME than in the DPPE group, but did not differ significantly ( 4 vs 2 dropout; $\chi^{2}=1.1$, NS). Weight losses from pretreatment to one-year averaged $7.8 \pm 3.7 \mathrm{~kg}$ for the DPME condition compared to $4.0 \pm 1.9 \mathrm{~kg}$ in the DPPE group. Again, there was a significant $(p<0.01)$. main effect of time, indicating that long-term weight losses were significant, but the time $\mathrm{x}$ group interaction was not significant $(p>0.10)$ suggesting that the changes in weight did not differ for the two groups. Because the distribution for weight loss was skewed, a median test was also conducted. Again, no significant difference between groups was observed (median weight loss of $-4.1 \mathrm{~kg}$ and $-2.6 \mathrm{~kg}$ for DPME and DPPE groups, respectively).

Although patients maintained their weight losses at one-year, improvements in other physiological parameters were not sustained. Changes in $\mathrm{HbA}_{1}$ $(-0.7 \pm 0.4 \%), \quad$ cholesterol $\quad(-0.16 \pm 0.16 \mathrm{mmol} / 1)$, triglycerides $(-0.02 \pm 0.54 \mathrm{mmol} / \mathrm{l})$ and HDL-C $(+0.03 \pm 0.05 \mathrm{mmol} / \mathrm{l})$ from pre-treatment to one-year were not significant, and no significant differences were observed between the DPME and DPPE groups.

Self-report data from the Paffenbarger Activity Questionnaire suggested that the failure to find differences between treatment groups may have been due to the failure to produce differences in activity levels. As would be expected, the DPME group reported greater increases in expenditure from walking during the treatment phase, than did the DPPE group $(+834$ vs $+406 \mathrm{kcal}, p<0.04)$. However, the increase in overall expenditure (walking plus other activity) was similar in the two groups (+976 vs $+1054 \mathrm{kcal}$, NS). Moreover, there were no significant differences between the two treatment groups in pre-treatment to one year changes in either calories from walking $(+483 \mathrm{vs}+132 \mathrm{kcal}, \mathrm{NS})$ or calories from total activity ( $+707 \mathrm{vs}+343 \mathrm{kcal}, \mathrm{NS}$ ).

Therefore, additional analysis of the 1 year data were conducted, comparing subjects in the low, medium, or high tertile for self-reported exercise at one year (regardless of their assigned treatment group). Subjects in the lowest exercise tertile reported expending $168-700 \mathrm{kcal} /$ week in exercise, compared to $700-1178 \mathrm{kcal}$ in the middle tertile and $1180-2212 \mathrm{kcal}$ in the highest tertile. Changes in $\mathrm{HbA}_{1}$ were related to activity tertile at 1 year $(p<0.0001)$; subjects who reported the lowest level of activity had an increase in $\mathrm{HbA}_{1}$ of $1.25 \%$ from pre-treatment to one year, compared to a decrease of $-1.0 \%$ and $-1.7 \%$ for the medium and high activity subjects. Activity level at one year was also related to weight change, $(p<0.001)$ with weight losses of $0.45 \mathrm{~kg}, 2.7 \mathrm{~kg}$, and $14.1 \mathrm{~kg}$ for the low, medium, and high exercise tertiles, respectively.

\section{Study 2}

Since the differences in activity between groups in Study 1 were small and not maintained at one-year, Study 2 was designed to produce more extreme differences between conditions. All 15 of the subjects assigned to the diet only group and 13 of the 15 assigned to diet plus exercise group in Study 2 completed the 10 week treatment period and were available at 1 year follow-up. Subjects in the diet plus exercise group attended an average of $96 \%$ of the assigned group exercise sessions while subjects in the diet only group attended $91 \%$ of their group meetings. Thus, attendance was high and did not differ significantly between conditions.

The Paffenbarger Activity Questionnaire data confirmed the difference in activity between groups during the initial 10 week treatment programme and showed that this difference was maintained at 1 year. Subjects in the diet plus exercise condition increased their overall caloric expenditure from $619 \mathrm{kcal} /$ week at baseline to $1522 \mathrm{kcal} /$ week at post-treatment and continued to expend $1561 \mathrm{kcal} /$ week at 1 year. In contrast, the diet only group maintained a low level of exercise through- 
Table 3. Change from pre-treatment to post-treatment (week 10) and 1 year follow-up for diet only and diet plus exercise conditions

\begin{tabular}{|c|c|c|c|c|c|}
\hline & \multirow{2}{*}{$\begin{array}{l}\text { Diet and exercise } \\
(n=13) \\
\text { mean } \pm \text { SEM }\end{array}$} & \multirow{2}{*}{$\begin{array}{l}\text { Diet only } \\
(n=15) \\
\text { mean } \pm \text { SEM }\end{array}$} & & \multicolumn{2}{|c|}{$p$-value for effect of } \\
\hline & & & & Time & $\begin{array}{l}\text { Time } \\
\mathbf{x} \\
\text { Group } \\
\end{array}$ \\
\hline \multicolumn{6}{|c|}{ Weight $(\mathrm{kg})$} \\
\hline Pre & $104.1 \pm 6.0$ & $102.0 \pm 5.0$ & & & \\
\hline Post & $94.8 \pm 5.9$ & $96.4 \pm 5.1$ & pre to post & 0.000 & 0.01 \\
\hline 1 year & $96.2 \pm 6.5$ & $98.2 \pm 4.9$ & pre to $1 \mathrm{yr}$ & 0.000 & 0.01 \\
\hline \multicolumn{6}{|c|}{ Body mass index $\left(\mathrm{kg} / \mathrm{m}^{2}\right)$} \\
\hline Pre & $37.47 \pm 1.89$ & $37.89 \pm 1.67$ & & & \\
\hline Post & $34.07 \pm 1.78$ & $35.84 \pm 1.78$ & pre to post & 0.000 & 0.02 \\
\hline 1 year & $34.55 \pm 2.08$ & $36.59 \pm 1.80$ & pre to $1 \mathrm{yr}$ & 0.001 & 0.009 \\
\hline \multicolumn{6}{|l|}{$\mathrm{HbA}_{1}(\%)$} \\
\hline Pre & $10.6 \pm 0.5$ & $10.9 \pm 0.5$ & & & \\
\hline Post & $8.2 \pm 0.3$ & $9.0 \pm 0.3$ & pre to post & 0.000 & NS \\
\hline 1 year & $9.2 \pm 0.5$ & $10.1 \pm 0.4$ & pre to $1 \mathrm{yr}$ & 0.002 & NS \\
\hline \multicolumn{6}{|c|}{ Cholesterol (mmol/1) } \\
\hline Pre & $4.86 \pm 0.31$ & $4.78 \pm 0.21$ & & & \\
\hline Post & $4.21 \pm 0.23$ & $4.44 \pm 0.16$ & pre to post & 0.0001 & 0.05 \\
\hline 1 year & $5.17 \pm 0.26$ & $5.20 \pm 0.21$ & pre to $1 \mathrm{yr}$ & 0.0001 & NS \\
\hline \multicolumn{6}{|c|}{ HDL-Cholesterol (mmol/l) } \\
\hline Pre & $1.01 \pm 0.07$ & $0.99 \pm 0.06$ & & & \\
\hline Post & $0.94 \pm 0.05$ & $0.96 \pm 0.05$ & pre to post & 0.02 & NS \\
\hline 1 year & $1.07 \pm 0.07$ & $1.09 \pm 0.07$ & pre to $1 \mathrm{yr}$ & 0.005 & NS \\
\hline \multicolumn{6}{|c|}{ Triglycerides $^{\mathrm{a}}(\mathrm{mmol} / \mathrm{l})$} \\
\hline Pre & $2.51 \pm 0.59$ & $1.82 \pm 0.25$ & & & \\
\hline Post & $1.42 \pm 0.19$ & $1.64 \pm 0.19$ & pre to post & 0.002 & 0.04 \\
\hline 1 year & $1.87 \pm 0.29$ & $1.85 \pm 0.18$ & pre to $1 \mathrm{yr}$ & NS & NS \\
\hline \multicolumn{6}{|c|}{ Systolic blood pressure $(\mathrm{mm} \mathrm{Hg})$} \\
\hline Pre & $132 \pm 5$ & $141 \pm 6$ & & & \\
\hline Post & $130 \pm 5$ & $135 \pm 6$ & pre to post & 0.06 & NS \\
\hline \multicolumn{6}{|c|}{ Diastolic blood pressure $(\mathrm{mm} \mathrm{Hg})$} \\
\hline Pre & $80 \pm 3$ & $84 \pm 3$ & & & \\
\hline Post & $83 \pm 2$ & $85 \pm 4$ & pre to post & NS & NS \\
\hline \multicolumn{6}{|c|}{ Fasting glucose $(\mathrm{mmol} / \mathrm{l})$} \\
\hline Pre & $11.6 \pm 0.6$ & $12.6 \pm 0.7$ & & & \\
\hline Post & $8.4 \pm 0.5$ & $9.2 \pm 0.7$ & pre to post & 0.000 & NS \\
\hline 1 year & $9.9 \pm 0.8$ & $11.8 \pm 1.0$ & pre to $1 \mathrm{yr}$ & 0.07 & NS \\
\hline \multicolumn{6}{|c|}{ Fasting insulin ${ }^{\mathrm{b}}(\mathrm{pmol} / \mathrm{l})$} \\
\hline Pre & $240 \pm 33$ & $175 \pm 30$ & & & \\
\hline Post & $183 \pm 31$ & $176 \pm 42$ & pre to post & 0.05 & NS \\
\hline
\end{tabular}

a Triglycerides were converted to logarithms for analysis; ${ }^{b}$ Insulin was converted to logarithms for analysis. Insulin was not measured in patients on insulin; insulin data were thus available for nine subjects in the diet plus exercise condition and ten in the diet only condition

out $(668,816,853$ at pre-treatment, post-treatment and 1 year, respectively). The changes in caloric expenditure from pre-treatment to post-treatment $(p<0.02)$ and from pre-treatment to 1 year $(p<0.01)$ were significantly greater in the diet plus exercise group than in the diet only group.

The two groups did not differ significantly in caloric intake; the diet only group reduced their intake from $1983 \mathrm{kcal} / \mathrm{day}$ at pre-treatment to $1163 \mathrm{kcal} / \mathrm{day}$ at post-treatment while the diet plus exercise group reduced from $1703 \mathrm{kcal}$ to $1086 \mathrm{kcal}$. Thus, if differences between the two groups are observed, they would appear to derive from differences in activity, not caloric intake.

Figure 1 shows that subjects in the diet plus exercise group lost significantly $(p<0.01)$ more weight than those in the diet only group at weeks 10,20 , and 62 . (The 20 -week data is based on 11 subjects in the diet plus exercise group and 7 in the diet only group who attended this assessment session.) Changes in body mass index were also significantly greater $(p<0.01)$ in the diet plus exercise condition at each time point.

As shown in Table 3, there were significant improvements in glycaemic control over the 10 -week treatment period, and despite some recidivism, $\mathrm{HbA}_{1}$ levels at one year were still significantly below pre-treatment levels. There were no significant differences between the two treatment conditions in $\mathrm{Hb}_{1}$ or fasting blood glucose at any time point.

The hypoglycaemic medication regimens which patients were following at weeks 0,10 and 62 were compared to determine whether there were differences 


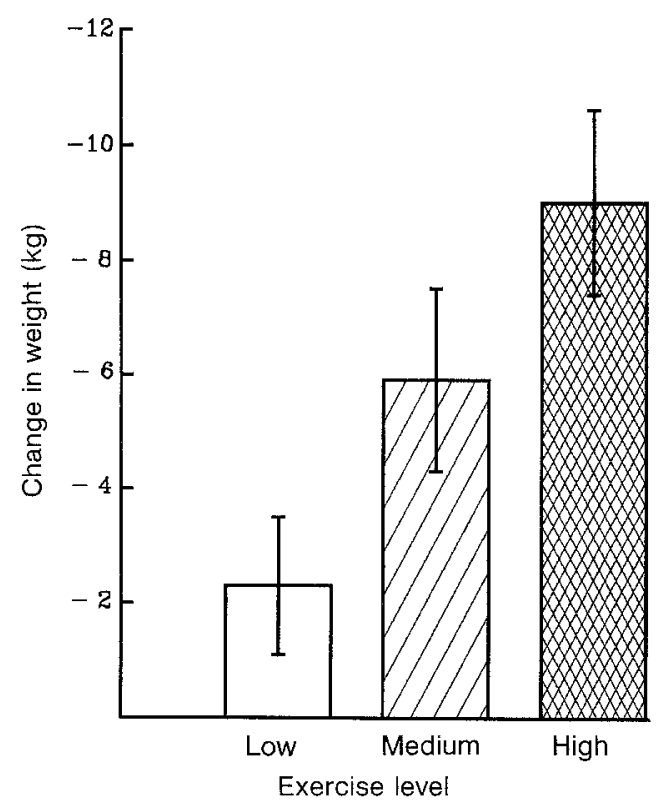

Fig. 2. Change in weight from pre-treatment to one year for patients who report low (168-615 kcal/week) ( $\square$ ), medium (700-1216 kcal/ week) (U) or high (1372-4116 kcal/week) exercise levels at one year (因), I=SEM

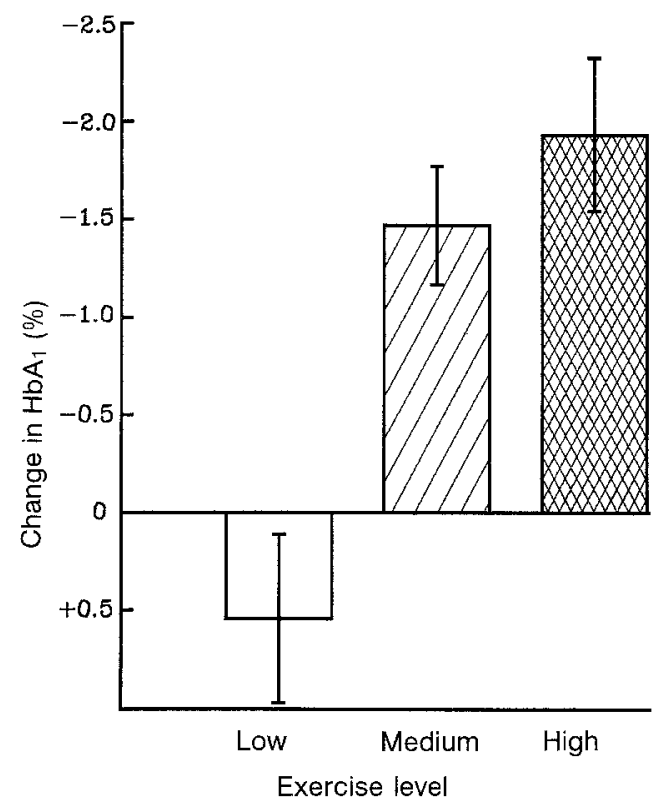

Fig. 3. Change in $\mathrm{HbA}_{1}$ from pre-treatment to one year for patients who report low (168-615 kcal/week) (口), medium (700-1216 kcal/ week) (שU) or high (1372-4116 kcal/week) exercise levels at one year (ख),$I=S E M$

between the two treatment conditions in the frequency or magnitude of medication changes. During the initial 10 weeks of the programme, a comparable percentage of the diet only and diet plus exercise patients had reductions in oral medication or insulin $(50 \%$ vs $67 \%$, NS). However, at 1 year follow-up reductions in medication in the diet plus exercise group were significantly more frequent and greater in magnitude than in the diet only group. Thirty eight percent of subjects in the diet only group who started the study on medication had reductions in their medication from pre-treatment to 1-year, compared to $83 \%$ of subjects in the diet plus exercise condition $\left(\chi^{2}=4.36, p<0.05\right)$. Moreover, the percent reduction in dosage of medication from pretreatment to 1 year was greater in the diet plus exercise condition $(p<0.01)$, with the median change being a $50 \%$ reduction in the diet plus exercise group compared to no change in the diet only group.

The diet plus exercise group had significantly greater reductions in total cholesterol $(p<0.05)$ and triglycerides $(p<0.04)$ than the diet only group from pre-treatment to 10 weeks (Table 2). Both groups also had significant decreases in HDL-C during this initial phase. At 1 year, there were significant increases in HDL-C and increases in total cholesterol, but there were no significant differences between treatment conditions.

\section{Combined analyses of studies 1 and 2}

Due to the similarity in study design, it was possible to combine the two studies to further investigate the relationship between exercise, weight loss and glycaemic control. The total sample from studies 1 and $2(n=45)$ was divided into tertiles according to self-reported exercise at 1 year $(\mathrm{low}=168-616 \mathrm{kcal} /$ week; medium $=$ $700-1200 \mathrm{kcal} /$ week; $\quad$ high $=1372-4116 \mathrm{kcal} /$ week). The tertiles were compared for the magnitude of weight loss and $\mathrm{HbA}_{1}$ change. As shown in Figures 2 and 3, the exercise tertiles differed significantly in weight loss $(-2.3,-5.9$, and $-9.1 \mathrm{~kg}$, for low, medium, and high levels of exercise respectively; $p<0.01)$ and $\mathrm{HbA}_{1}$ change $(+0.5 \%,-1.5 \%$, and $-1.9 \% ; p<0.001)$.

Similar results were seen with rank order correlational analysis. For the sample as a whole, exercise at 1 year correlated with weight loss $(r=-0.57, p<0.001)$ and with decreases in $\mathrm{HbA}_{1}(r=-0.54, p<0.001)$. Thus subjects who reported the highest activity levels lost the most weight and had the greatest decreases in $\mathrm{HbA}_{1}$. Moreover, although change in weight and change in $\mathrm{HbA}_{1}$ were related to each other $(r=0.38$, $p<0.05$ ), the effect of exercise on change in $\mathrm{HbA}_{1}$ was independent of the effect of weight loss. Exercise level at 1 year was related to improvements in $\mathrm{HbA}_{1}$ $(r=0.44, p<0.05)$, even after adjusting for the effects of weight loss.

\section{Discussion}

The main finding of these studies was that diet and exercise produced larger weight losses and greater reductions in hypoglycaemic medication than diet only. Moreover, those patients who reported the highest exercise levels at 1 year had both the largest weight losses and the greatest improvements in glycaemic control, independent of weight loss. 
In Study 1, we compared a diet plus moderate exercise group with a diet plus placebo exercise. No significant differences were observed between the two groups at the end of the 10 week programme or at 1 year follow-up. The failure to find differences between treatment groups seemed to be due to the fact that patients in both conditions increased their activity level over the course of the programme. Thus, it appears that a placebo exercise programme such as the one utilised here, which involved light calisthenics set to music and which was conducted in a group format, may lead to a general increase in activity in previously sedentary patients.

The second study compared two more extreme conditions, diet only and diet plus exercise. This study was more successful in producing differences in self-reported activity both at the end of the 10 week programme and at one year follow-up and showed significant differences in weight loss at all time points studied. Since changes in self-reported caloric intake were similar in the two treatment groups, these differences in weight loss seem to be due to differences in caloric expenditure. Moreover, changes in medications from pretreatment to 1 year were more frequent and greater in magnitude for patients in the diet plus exercise group than for those in the diet only group, showing that improved glycaemic control could be obtained with lower doses of hypoglycaemic medications in patients treated with diet plus exercise.

These results contrast with previous studies in the diabetes literature which have failed to show a benefit of diet plus exercise compared to diet only. Bogardus et al., [15] for example, found comparable weight losses for patients given diet only, and diet plus exercise $(-9.9$ vs $-11.1 \mathrm{~kg}$ ) at the end of the 12 week intervention. There were also comparable improvements in fasting plasma glucose and meal tolerance, with decreases in endogenous glucose production and increased hepatic sensitivity to insulin. Only the mechanism differed, with the exercise group showing a greater increase in apparent carbohydrate storage rates. Subjects in the Bogardus et al. [15] study followed a very strict diet of approximately 600 calories/day. With this strict diet, a maximum rate of weight loss/week may have been obtained, overshadowing any effects of exercise. This explanation is supported by the fact that the diet and exercise group in athe Bogardus study and in the present study had similar short term weight losses (11.1 vs $9.2 \mathrm{~kg}$, respectively). However, subjects in the diet only group in the Bogardus study lost more weight than subjects in the diet only group in the present study ( $9.9 \mathrm{vs} 5.6 \mathrm{~kg}$ ).

Other studies with diabetic patients have also failed to find a benefit of diet plus exercise. Saltin [17] found no difference in weight loss for patients who were given diet only or diet plus exercise (mean $=4.5 \mathrm{~kg}$ ), but both groups did better than an exercise only condition. Kaplan [16] found superior weight losses at 3 months for patients given diet only compared to those given diet plus exercise $(3 \mathrm{~kg}$ vs $0.2 \mathrm{~kg}$ ). These studies with diabetic patients contrast with several studies with nondiabetic subjects which show that the combination of diet plus exercise produces better weight losses than diet only [5-8]. In these studies, weight loss of patients treated with diet only and diet plus exercise were comparable at the end of the initial 10-12 week treatment programme, but the diet plus exercise condition produced significantly greater weight losses at 6-12 month follow-up. In the present study, significant effects of adding exercise to the programme were seen at both 10 weeks and at 1 year follow-up. It is difficult to know how to reconcile these differences among studies. It is possible that some of the differences are due to the actual levels of activity obtained as compared to the level of prescribed activity. It may be helpful in subsequent studies to include measures of self-reported activity level and to analyse the data as a function of both prescribed and obtained activity levels.

The only prior study to include placebo exercise [30] found trends but no significant difference in outcome for adults who participated in a diet programme which included either aerobic exercise, lifestyle exercise, or placebo exercise (calisthenics). Again, the placebo exercise condition may have led to more general increases in activity level. Alternatively, these findings with placebo exercise conditions may suggest that some of the effects usually ascribed to exercise may be due to non-specific effects of exercise (e.g. time spent away from food, psychological benefits from exercise or from social interaction).

The most striking evidence of the benefits of exercise are shown in the analyses comparing patients who report high, medium, and low activity levels. Activity level at 1 year was strongly associated with weight loss and with improvements in $\mathrm{HbA}_{1}$ even after adjusting for the effects of weight loss. These data confirm epidemiological studies which show a relationship between activity level and glucose tolerance [32, 32].

These studies did not include measures of cardiovascular fitness, since the goal of the interventions was to increase activity level and consequently caloric expenditure, rather than to increase cardiovascular fitness. The distinction between cardiovascular fitness and activity is frequently overlooked, but it is possible to increase activity and hence caloric expenditure without attaining the intensity, frequency, and duration of activity required to promote cardiovascular fitness. Moreover, it is unclear whether it is activity or fitness (or neither) that is related to glycaemic control. Epidemiological studies suggest that activity level may be related to glucose tolerance [31] and to the development of Type 2 diabetes [32], but to date most intervention studies have used exercises that promote cardiovascular fitness (e.g. 10, 15). Further research is needed to compare the effect on glycaemic control of interventions that promote cardiovascular fitness and those that increase activity (but not fitness). 
Finally, the present study replicates previous research from our laboratory on the effectiveness of behavioural weight control programmes for diabetic patients. We have recently reported weight losses of $6.2 \mathrm{~kg}$ at the end of 12-weeks and $6.1 \mathrm{~kg}$ at one-year follow-up [33]; those results are quite comparable to the findings in the present study. To date there are few controlled studies of long-term weight loss in diabetic patients [4], but the results of the present study appear comparable or superior to those usually reported.

In conclusion, the combination of diet and exercise appears to be of value in the treatment of patients with Type 2 diabetes. Patients who maintained the highest levels of exercise show the best long-term weight loss and improvements in glycaemic control.

Acknowledgements. This investigation was supported by grant AM 29757-07 from the National Institutes of Health, Bethesda, Md, USA.

\section{References}

1. Doar JWH, Wilde CE, Thompson ME, Sewell PFJ (1975) Influence of treatment with diet alone on oral glucose-tolerance test and plasma sugar and insulin levels in patients with maturity onset diabetes mellitus. Lancet I: 1263-1266

2. Olefsky J, Reaven GM, Farquhar JW (1974) Effect of weight reduction on obesity: studies of lipid and carbohydrate metabolism in normal and hyperlipoproteinemic subjects. J Clin Invest 53: 64-76

3. Reaven GM (1983) Introduction; the role of insulin resistance in the pathogenesis and treatment of non-insulin dependent diabetes mellitus. Am J Med 74: 1-2

4. Wing RR (1985) Improving dietary adherence in patients with diabetes. In: Jovanovic L, Peterson CM (eds) Nutrition and diabetes. Liss, New York, pp 161-186

5. Dahlkoetter J, Callahan EJ, Linton J (1979) Obesity and the unbalanced energy equation: exercise vs eating habit change. $\mathrm{J}$ Consult Clin Psychol 47: 898-905

6. Harris MB, Hallbauer ES (1973) Self-directed weight control through eating and exercise. Behav Res Ther 11: 523 -529

7. Stalonas PM, Johnson WG, Christ M (1978) Behaviour modification for obesity: the evaluation of exercise, contingency management, and programme evaluation. J Consult Clin Psychol 46: 463 -469

8. Epstein LH, Wing RR, Koeske R, Valoski A (1984) Effects of diet plus exercise on weight change in parents and children. $J$ Consult Clin Psychol 52: 429-437

9. Reitman JS, Vasquez B, Klimes I, Nagulesparan M (1984) Improvement of glucose homeostasis after exercise training in noninsulin-dependent diabetes. Diabetes Care 7: 434-441

10. Schneider SH, Amorosa LF, Khachadurian AK, Ruderman NB (1984) Studies on the mechanism of improved glucose control during regular exercise in Type 2 (non-insulin-dependent) diabetes. Diabetologia 26: $355-360$

11. Trovati M, Carta Q, Cavalot F, Vitali S, Banaudi C, Lucchina PG, Fiocchi F, Emanuelli G, Lenti G (1984) Influence of physical training on blood glucose control, glucose tolerance, insulin secretion, and insulin action in non-insulin-dependent diabetic patients. Diabetes Care 7: 416-420

12. Bjorntorp P, Holb G, Jacobson B, Schiller-deJounge K, Lundeberg P, Sjostrom L, Smith U, Sullivan L (1977) Physical training in human hyperplastic obesity IV. Effects on the hormonal status. Metabolism 26: 319-328

13. DeFronzo RL, Ferrannini E, Koivisto V (1983) New concepts in the pathogenesis and treatment of non-insulin-dependent diabetes mellitus. Am J Med 74: 52-81
14. Wood PD, Haskell WL (1979) The effect of exercise on plasma high density lipoproteins. Lipids 14: 417-427

15. Bogardus C, Ravussin E, Robbins DC, Wolfe RR, Horton ES, Sims EAH (1984) Effects of physical training and diet therapy on carbohydrate metabolism in patients with glucose intolerance and non-insulin-dependent diabetes mellitus. Diabetes 33: 311-318

16. Kaplan RM, Wilson DK, Hartwell SL, Merino KL, Wallace JP (1985) Prospective evaluation of HDL cholesterol changes after diet and physical conditioning programmes for patients with Type 2 diabetes mellitus. Diabetes Care 8: $343-348$

17. Saltin B, Lindgarde F, Houston M, Horlin R, Nygaard E, Gad P (1979) Physical training and glucose tolerance in middle-aged men with chemical diabetes. Diabetes 28 [Suppl 1]: 30-32

18. American College of Sports Medicine (1980) Guidelines for Graded Exercise Testing and Exercise Prescription. Lea and Febiger, Philadelphia

19. National Diabetes Data Group (1979) Classification and diagnosis of diabetes mellitus and other categories of glucose intolerance. Diabetes 28: 1039-1057

20. American Diabetes Association (1979) Principles of nutrition and dietary recommendations for individuals with diabetes mellitus: 1979. Diabetes 28 : 1027-1029

21. Metropolitan Life Insurance Company (1983) Metropolitan height and weight table. Stat Bull Metrop Insur Co 64: 2-9

22. Cohen JD, Grimm RH, Smith WM (1981) Multiple risk factor intervention trial (MRFIT) VI. Intervention on blood pressure. Prev Med 10: 501-518

23. Allain CC, Poon LS, Chan CSG, Richmond W, Fu PC (1974) Enzymatic determination of total serum cholesterol. Clin Chem 20: $470-475$

24. Bucolo G, David H (1973) Quantitative determination of serum triglycerides by the use of enzymes. Clin Chem 19: 476-482

25. Albers JJ, Warnick GR, Wiebe D, King P, Steiner P, Smith L, Breckenridge $C$, Chow A, Kuba W, Weidman $S$, Arentt $H$, Wood P, Schlagenhaft A (1978) Multi-laboratory comparison of three Heparin-Mn $2^{+}$precipitation procedures for estimating cholesterol in high-density lipoproteins. Clin Chem 24:853-856

26. Herbert V, Lau KS, Gottlieb CW (1965) Coated charcoal immunoassay of insulin. J Clin Endocrinol 25: 1375-1384

27. Koenig RJ, Peterson CM, Jones RL, Saudek C, Lehrman M, Cerami $A$ (1976) Correlation of glucose regulation of hemoglobin A $1 \mathrm{c}$ in diabetes mellitus. N Engl J Med 295: 417-420

28. Daneman D, Wolfson DH, Becker DJ, Drash AL (1981) Factors affecting glycosylated hemoglobin values in children with insulindependent diabetes. J Pediatr 99: 847-853

29. Paffenbarger RS Jr, Wing AL, Hyde RT (1978) Physical activity as an index of heart attack risk in college alumni. Am $\mathrm{J}$ Epidemiol 108: $161-175$

30. Epstein LH, Wing RR, Koeske R, Valoski A (1985) A comparison of lifestyle exercise, aerobic exercise, and calisthenics on weight loss in obese children. Behav Ther 16:345-356

31. Montoye HJ, Block WD, Metzner H, Keller JB (1977) Habitual physical activity and glucose tolerance. Diabetes $26: 172-176$

32. Taylor R, Ram P, Zimmet P, Raper LR, Ringrose H (1984) Physical activity and prevalence of diabetes in Melanesian and Indian men in Fiji. Diabetologia 27:578-582

33. Wing RR, Epstein LH, Nowalk MP, Scott N, Koeske R, Hagg S (1986) Does self-monitoring of blood glucose improve dietary compliance for obese patients with Type 2 diabetes? Am J Med 81: $830-836$

Received: 10 May 1988

and in revised form: 24 October 1988

\section{Dr. R. R. Wing}

University of Pittsburgh School of Medicine

Western Psychiatric Institute and Clinic

3811 O'Hara Street

Pittsburgh, Penn 15213

USA 